\title{
The Relationship Between Supply Chain Management and ERP in E-Business
}

\author{
Dawei Liu \\ Institute of Management Science and Information Engineering, Hangzhou Dianzi \\ University, Hangzhou 310018, P.R. China hduldw@163.com
}

\begin{abstract}
Supply Chain Management (SCM) in today's global environment, especially the E-business is important to create significant competition advantages to firms and business partners worldwide. Since the objectives and goals are essential factors in the study of supply chain management in the Ebusiness. The purpose of this research paper is to present the research question, review the conceptual framework, ERP and environment for SCMS, study their objectives, impact of SCM and utilize any useful theories that may help to identify the critical factors of SCM. The differences of Pre-Internet and Ebusiness are also presented to clarify further research opportunities in this field.
\end{abstract}

Keywords: Supply chain management, SCM, E-business, ERP

\section{SUPPLY CHAIN MANAGEMENT AND E-BUSINESS}

Supply Chain Management (SCM) is the systematic theory and practical tools to provide integrated supply chain to the "Supply Value Chain" in order to meet customers' satisfaction needs and expectation requirement [1]. The process of SCM is from suppliers of raw materials through manufacturing and on to end-customers. With the quick development of Internet, E-commerce is not simply about business transactions that run over the internet, but is fundamentally about the flow of information [2]. The boundaries of organizations are more fluid and flexible than they used to be 20 years before.

Supply chain management drives companies to streamline the ways they manufacture, distribute, and sell products and finally will change the strategies of firm The supply chain cycle starts with a customer's requirement and the manufacturer delivers the order through the process of the firm, for example, sales, marketing, producing, distribution, purchasing, and selling. In regular style the manufacturer may search the outside support from suppliers, utilities, transportation, and other providers of goods and services that are essential to make the products and services customer required [4]. The information exchange pertains to such matters as requests for quote, bids, purchase orders, order confirmations, shipping documents, invoices and payment information et.. In this procedure multiple enterprises within a limited market collaboratively plan, practice, and manage the flow of goods, services, and information along the value system in the same way to increase customer-perceived value and optimizes the efficiency of the chain.

Please use the following format when citing this chapter:

Liu. D., 2007. in IFIP International Federation for Information Processing. Volume 254. Research and Practical Issues of Enterprise Information Systems II Volume 1. eds. L. Xu. Tjoa A., Chaudhry S. (Boston: Springer), pp. 269-273. 
There is no arguing that cutting the cost is a critical challenge for firms. Creating more value and cutting costs raise a question for the practitioners to solve with the intensive competition globalization. New methods and theories, such as OTM, Zero Deposit, CRM, ERP, are take to satisfy stock owners' desire [5]. Among these new inventions, expanded inventories stand out as the most critical that have a huge impact on the company's bottom line. Inventories include raw materials, work in progress, and finished products. Businesses incur costs associated with storing, distributing, warehousing and transporting these products. It is discussed that the product manufacturing usually occurs between the business entities that include the manufacturer, the distributor, and the retailer [6]. This chain, mainly consisted by the three parts is referred to as the supply chain. According to Kehoe, Dennis, and Nick the supply chain is a set of three or more companies directly linked by one or more of the upstream and downstream flows of products, services, finances, and information from a source to a customer $[7,8]$.

The question focused on the companies that are trying to thrive in a difficult business environment is: What kind of strategies can practitioner take to operate the firm in lower operational costs, boost performance, and enhance upstream and downstream collaboration in order to survive and grow in today's competitive global environment? While recognizing the importance of the answer, it is as important to understand what lies ahead for Supply Chain Management (SCM) [9].

The aim of this paper is to study the prospects of the research question: How is the objectives of SCMS in future business, especially in E-business? The justification for the research question is that it provides a direction for organization on up-to-date technologies that can prove useful and would lead to building a successful SCMS. Factors, such as ERP, CRM, ECT, EDI, that have an influence on organization's decision to use a certain kind of "new" technology. Practitioners may focus on opportunities to influence the critical factors, while scholars may point out common factors among different technologies and may generalize to a wider scope, including traditional fields and high-tech fields.

\section{SUPPLY CHAIN MANAGEMENT STRUCTURES}

Supply Chain Management, claimed to be the next cost cut strategy and tool by many scholars is defined as a set of approaches utilized to integrate suppliers, manufacturers, warehouses, and stores [10]. In this condition merchandise is produced and distributed at the right quantities, to the right locations, and at the right time, in order to minimize system wide costs and raise profit while satisfying the requirements from the customers. SCM functionality for manufacturers includes full management of the scheduling and acquisitions of the materials needed for production [11].

SCM is integrated greatly with internal functions of the enterprises that may include HR, sales and marketing, manufacturing, and finance through Enterprise Resource Planning Systems (ERP). Enterprises are leaning more towards improving their supply chains due to the growth in the number of suppliers that require them to 
have more efficient and effective SCM systems. At the same time firms dependence on outsourcing logistics of the supply chain is also asking their improvement to meet customers' needs. Enterprises are aiming to create transparency and visibility into the supply chain in order to fulfill their business objectives [12]. Supply chain partners are able to cooperate when there is transparency in the supply chain. Vendors and suppliers can support the chain more efficiently and effectively when information moves across the chain in a timely manner.

Stephen and Gaughran argue the inevitable change of organizational structure in their discussion on the integration of supply chain. They insist that firms need to adopt new systems that cannot be observed in the traditional organization structure where independent functional areas such as production and marketing prevail, in order to shift to integrated supply chain management. Therefore a total new department should be founded to take charge of the changes caused by SCM. In other words, organization type which considers the role and status of independent department responsible for supply chain management (SCM) activities, should be clearly established. There is no arguing that many firms recognizing the importance of supply chain management have begun adopting new organizational structure [13]. However, it is a hard task to describe a single type of organization that is suitable for all the styles of supply chain management.

A hard choice have to be made by enterprises because even if a firm makes the establishment of a new department for supply chain management. Whether the new department is located in an independent place or incorporated into an appropriate existing department must be made. The decision will relocate the power and resources in the firm. Also, in case of creating a new independent department, the determination on operational role and hierarchical relationship within organization between new SCM department and existing departments should be followed [14]. And various industrial and environmental characteristics of each firm should be recognized. This difficulty makes the position of SCM department within an organization extremely sensitive, which is a rarely seen phenomenon in production or sales departments because the independent and solid status of these departments does not change regardless of how a firm may be restructured.

\section{SUPPLY CHAIN MANAGEMENT AND ERP}

Enterprise Resources Planning (ERP) system offers a viable management capability to helping enterprise in particular manufacturing enterprises manage the resources. The rapid growth in technologies and innovation in manufacturing and information processing is pushing companies into a new paradigm shift. Numerous companies that have successfully implemented ERP systems testified to its life-saving importance [15]. However, enterprises must not be haste to embrace ERP projects. The urgent project planning and poor adoption of ERP may mean realigning the enterprises' comparative advantage position which enterprises can dearly afford.

ERP projects adoption has been the most important tool of the larger organizations. Features and business process flow have been designed based on 
practices by practitioners in the large organizations. Consulting and project management methodologies are normally specified based on such experiences. The needs, operating requirements, logistics fulfillment and financial capabilities of the SME manufacturers are vastly different from that of the large and medium sized manufacturers. For small and medium firms, development of information technologies is key factors for the objective of their own. Adoption of information technology by small and medium firms in managing their ERP projects is also limited [16]. While ERP is sufficiently flexible to cope with the general manufacturing enterprises, we need to take a closer look at the strategic and operational needs of small and medium firms before we can properly develop a project management strategy for them.

As discussed above, enterprise resources in the firms are subjected to the effect of interactions. The interdependencies move in different ways to achieve its own set of objectives. Various enterprise resources should be coordinated and integrated for the pursuit of the firm's interdependencies. Given the complexities in understanding the dynamics involved in managing these resources in a firm, the less important part of the ERP is a three-level ERM architecture combining system dynamics modeling with multi-agent-based approach. This model reduces the cluster dynamics existing amongst the various enterprise resources within the firms, the understanding will greatly aid in project management of ERP systems in enterprises. The various enterprise resources in a firm can be segregated into different agents. An agent must have at least an objective or goal. When realizing the objective, the agent acts autonomously. The act matches the organization dynamics relationship well. Like the operational managers in a firm, agents can have several roles in the procedure of the organization operation.

In this three-level ERM architecture, each agent plays only one of the roles, e.g. execution, planning, and coordination. The plan of the ERM considers the possible decentralization of information, resources, and the decision-making processes commonly found in firms. Also this three-level model rejects the "low levels of management structure" typical of enterprise. The first level, the operational level, consists of execution agents which receive plans from the planning agent. The second level, the decision level, comprises of the various planning agents (typically associated with the planning and operational management in the SME). At the top level lies the coordination agent, who provides "global" information and strategic directions for the planning agents to produce quality multi-agent plans.

\section{CONCLUSIONS}

With the understanding of SCM objectives and its future in E-business, more attention should be paid to search a high effective way to promote the ability of SCM. Customer intimacy and customer loyalty are the base of our SCM to gain extra profit in E-business, which means enterprises must adapt the new tendency to gain the advantage in the competition. And these can be approach by: 
Firstly, ability to respond quickly to customers' requests for proposals and requests for changes by involving the appropriate technical and management skills at all project sites;

Secondly, better exploitation of the network resources, thanks to a decisionsupport environment which is aware of co-operation possibilities (e.g. roles to be fulfilled in a project under planning) and available partners' skills and capacities;

Thirdly, prompt negotiation of planning and re-planning options, by means of a communication infrastructure that circulates decisions and events between the appropriate actors, crossing companies and organizational unit boundaries.

\section{REFERENCES}

1. S. Chen, B. Mulgrew, and P.M. Grant, A clustering technique for digital communications channel equalization using radial basis function networks, IEEE Trans. Neural Networks. Volume 4, pp.570-578, (1993).

2. M. Heller, Will XML Ever Make Good On Its Promise?, CIO. pp.114-119, (May 2001).

3. M. Stein and F. Voehl, Macrologistics Management (St. Lucie Press: 1998), pp.55-69.

4. R.R. Levary, Better Supply Chains Through Information Technology, Industrial Management. Volume 42, Number 3, pp.24-30, (2000).

5. J. Herman, XML e-business Standards Converge, Business Communication Review. Volume 31, Number 10, pp.24-26, (2001).

6. J.H. Dobbs, Competition's New Battleground: The Integrated Value Chain (Cambridge Technology Partners: 1998).

7. D. Kehoe and N. Boughton. Internet Based Supply Chain Management A Classification Of Approaches To Manufacturing Planning And Control, International Journal of Operations \& Production Management. Volume 21, Number 4, pp.44-57, (2001).

8. H. Lucas and V. Spitler, Technology Use and Performance: A Field Study of Broker Workstations, Decision Sciences. Volume 30, Number 2, pp.291-311, (1999).

9. A. Patrizio, XML Passes From Development To Implementation, InformationWeek. Volume 830, pp.116-120, (2001).

10. Patterson, A. Kirk, C.M. Grimm, and M.C. Thomas, Diffusion of Supply Chain Technologies, Transportation Journal. Volume 43, Number 3, pp.5-24, (2004).

11. C. Robson, Real World Research: A Resource for Social Scientist and Practitioners, 2nd Edition (Blackwell Publishers: 2002), pp.472-481.

12. S. Levi, E. David, and P. Kaminsky, Designing and Managing the Supply Chain (McGraw-Hill Higher Education: 2000), pp.16-19.

13. S.Z. Sleeper, Dynamic Supply Chains Combine EDI, XML In An Effort To Transition To The Web, High-Tech Supply On-the-Fly. pp. 87-92, (November 2000).

14. W.H. Delone and E.R. McLean, Information Systems Success: The Quest for the Dependent Variable, Information Systems Research. Volume 3, Number 1, pp.60-95, (1992).

15. R.W. Schmenner, Production/Operations Management (Science Research Associates: Chicago, 1987).

16. Z.G. Zacharia, The Evolution and Growth of Information Systems in Supply Chain Management, in Supply Chain Management, eds. J.T. Mentzer (Sage Publications: 2001), pp.289-319. 